\title{
Management of Painful Bone Metastases: The Interaction between Radiation Therapy and Zoledronate
}

\author{
Rossella Di Franco ${ }^{1}$, Mariagrazia Calvanese ${ }^{1}$, Mariagrazia Cuomo ${ }^{1}$, Roberto Manzo $^{2}$, Paola Murino ${ }^{2}$, \\ Salvatore Cappabianca ${ }^{1}$, Vincenzo Ravo ${ }^{2 *}$
}

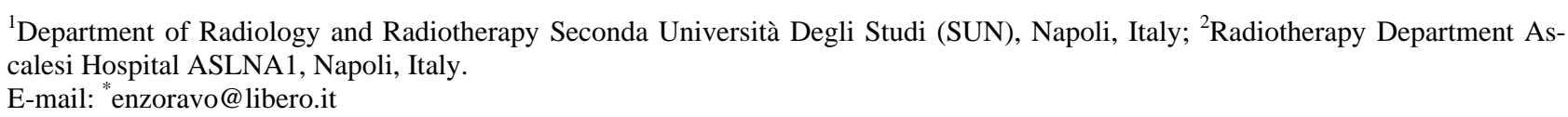

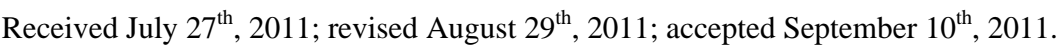

\begin{abstract}
Background: Advanced cancers frequently metastasize to bone, and the presence of bone metastases is the most common cause of cancer-related pain. Pain management requires a multidisciplinary approach that involves the use of analgesics, bisphosphonates, radiotherapy, chemotherapy, surgery. The aim of our study was to evaluate the enhancement of radiotherapy on painful bone metastases in patients treated also with bisphosphonates. Materials and Methods: We analyzed the differences in benefit on pain and on quality of life comparing two groups of treatment. The first group comprised 104 patients treated with Radiotherapy $(R T)$, the second one included 50 patients treated with radiotherapy associated to zoledronic acid $(R T+Z)$. All patients completed before, during and after treatment, a questionnaire that rated the grade of pain, the pharmacological type of analgesic therapy and patient's performance status. For each patient a total score was calculated, from a minimum value of $0 \%$ to a maximum of $20 \%$, then expressed as a percentage. Patients were classified as responder if at the follow-up reported a reduction of over $20 \%$ of the initial score, no change if there was a reduction of between $0 \%$ and $20 \%$, progression if there was an increasing of the score. Results: In the group $R T+Z$ we found fewer patients that started radiation therapy with severe pain (16\% vs 32\%), no patient had pain of grade 10 , and a higher proportion of asymptomatic patients (12\% vs $4 \%)$ was observed. In the RT alone group a higher percentage of patients started treatment assuming strong opioid more than once a day (26\% vs 24\%) and a reduction in number of these patients was about $14 \%$ compared with the reduction of $23.6 \%$ observed in the group $R T$ $+Z$. Furthermore an increased total score was calculated only in the $6 \%$ of patient belonged to group RT alone. Finally, in the group $R T+Z$ responder patients are $52 \%$, compared to $36 \%$ of the $R T$ group, non-responder were $36 \%$ versus $60 \%$ in the $R T$. The risk of adverse events $(\mathrm{Pz})$ in the $R T+Z$ was $P z=0.36$, with an odds $(\mathrm{Oz})$ equal to 0.56 , while the risk of adverse events $(P c)$ in the $R T$ group was $P_{C}=0.60$ with an odds $\left(O_{C}\right)$ of 1.5. The odds ratio was $O R=0.37$, showing a value in favor of treatment $R T+Z$. Conclusions: In our retrospective observational study it is relevant a clear potentiation of benefit effects related to palliative radiation therapy in patients receiving also bisphosphonate therapy, so obtaining a better control over pain, a decreased need for pain relief and consequently an improved quality of life.
\end{abstract}

Keywords: Bone Metastases, Radiotherapy, Zoledronate

\section{Introduction}

Many cancers metastasize to bone exhibiting a particular osteotropism. Bone is the third most common metastatic site after the lung and the liver. Bone metastases, a frequent and severe complication in the evolution of neoplastic disease, are more often seen in male patients with lung or prostatic cancer and in female patients with breast cancer. The presence of bone metastases is the most common cause of cancer-related pain [1-3], and management, often difficult, pain requires a multidisciplinary approach to therapy [4] which provides, as appropriate, the use analgesics, bisphosphonates, radiotherapy, chemotherapy, surgery [5].

Radiotherapy is considered a standard treatment in the management of bone metastases, particularly in presence of pain, risk of pathological fracture or spinal cord com- 
pression. Hypofractionated irradiation continues to be the treatment regimen most frequently used [4]. Bisphosphonates, treatment of choice for hypercalcemia of bone resorption, can reduce pain, the risk of fractures and the development of new osteolytic lesions and, consequently, improve the quality of life of patients $[5,6]$.

\section{Methods and Materials}

From February 2008 to December 2010, 154 patients, aged between 31 and 92 years with bone metastases were treated or in the Radiotherapy Department of the Seond University of Naples or in the Radiotherapy Department of Ascalesi Hospital, with a palliative intent. Patients were associated to two groups. The first one included 104 patients treated with Radiotherapy alone; the second one included 50 patients treated with Radiotherapy associated to Zoledronic acid (RT $+\mathrm{Z}$ ) given at a dose of 4 $\mathrm{mg} / 100 \mathrm{ml}$ with an infusion of 15 ' i.v. every 4 weeks. The most common primary site involved was the breast, accounting for 50 (32\%) patients, followed by lung with 30 (20\%) patients, prostate with $20(13 \%)$ patients. The most frequent site of metastasis was located in the pelvis (37\%), followed by the lumbar spine (24\%) and thoracic spine (18\%).

All patients were treated with $6 \mathrm{MV}$ photons from a linear accelerator adopting or the common hypofractionated course schedule (30 Gy/10 fractions) or a short radiation course (8-20 Gy/1-4 consecutive fractions). The assignment to one of the treatment schedule was not randomized but decided on the basis of the site and the number of metastases (single or multiple), the extent of radiation field, the risk of bone fracture, the performance status, and the expected life span of patient. Fast courses were used when there was a risk of bone fracture in limbs; however, fast courses were avoided in location within the trunk when large irradiation fields were required. On the contrary, conventional fractionation was preferred in patients with good performance status and a long expected life span, as reported in other experiences [7].

The site distribution and patient characteristics in the two treatment arms are summarized in Table 1.

The aim of our study was to analyze the differences in benefit on pain and quality of life obtained in the two treatment groups assessing the extent of enhancement on the benefits given by radiation therapy in patients who also underwent treatment with bisphosphonates.

All patients completed a questionnaire before, during, and after 30th, 60th and 90th days from the end of radiation therapy. The questionnaire pointed out the pain with a score from 0 (indicating no pain) to 10 (greater pain possible) using a numerical scale (NRS), the analgesic therapy assigning a score from 0 to 6 depending on the type of drug used and the frequency of daily intake, valutation of performance status by ECOG/WHO assigning a score from 0 to 4 . Thus, a total score was calculated, for each patient, from a minimum of 0 to a maximum of 20 , expressed as a percentage: a value $0 \%$ described a patient with no pain, that made no use of analgesics and with a normal performance status; a value of $100 \%$ described, instead, a patient who had intolerable pain (NRS $=10$ ) and for this he assumed strong opioids more than 1 time for day, and completely bed-bound (Table 2). For the two groups of patients was then calculated the variation of the total score considering the value at the start of radiation treatment, at the sixtieth, or the ninetieth day after the end of treatment. Patients who showed a reduction of the score greater than $20 \%$ were classified as responder, those who showed a reduction of the score between $0 \%$ and $20 \%$ were reported as nochange, patients who experienced an increase of the score were considered progression.

Table 1. Baseline demographic and disease characteristics of patients with bone metastases.

\begin{tabular}{|c|c|c|c|}
\hline \multirow{2}{*}{ Characteristics } & \multicolumn{3}{|c|}{ Treatment group } \\
\hline & (RT) & $(\mathrm{RT}+\mathrm{Z})$ & \\
\hline No. of patients & 104 & 50 & Total 154 \\
\hline \multicolumn{4}{|l|}{ Sex } \\
\hline Female & 56 & 20 & 76 \\
\hline Male & 48 & 30 & 78 \\
\hline \multicolumn{4}{|l|}{ Age } \\
\hline $\begin{array}{l}\text { Median (range) age, } \\
\text { years }\end{array}$ & $63(31-92)$ & $66(46-82)$ & \\
\hline \multicolumn{4}{|l|}{ Histology } \\
\hline Breast & 30 & 20 & $50(32 \%)$ \\
\hline Prostate & 6 & 14 & $20(13 \%)$ \\
\hline Lung & 20 & 10 & $30(19 \%)$ \\
\hline Liver & 8 & 0 & $8(5 \%)$ \\
\hline Colon & 4 & 2 & $6(4 \%)$ \\
\hline Rectum & 4 & 0 & $4(2,5 \%)$ \\
\hline Bladder & 8 & 0 & $8(5 \%)$ \\
\hline Kidney & 6 & 2 & $8(5 \%)$ \\
\hline Larynx & 4 & 0 & $4(2,5 \%)$ \\
\hline Pleura & 4 & 0 & $4(2,5 \%)$ \\
\hline Thyroid & 2 & 2 & $4(2,5 \%)$ \\
\hline Parotid & 2 & 0 & $2(1 \%)$ \\
\hline Mouth & 2 & 0 & 2 (1\%) \\
\hline Unknow & 4 & 0 & $4(2,5 \%)$ \\
\hline \multicolumn{4}{|l|}{ Metastasis site } \\
\hline Cervical spine & 2 & 2 & 4 (2\%) \\
\hline Thoracic spine & 20 & 16 & $36(18 \%)$ \\
\hline Lumbar spine & 32 & 16 & $48(24 \%)$ \\
\hline Pelvis & 56 & 18 & $74(37 \%)$ \\
\hline Femur & 8 & 10 & $18(9 \%)$ \\
\hline Tibia & 4 & 0 & $4(2 \%)$ \\
\hline Scapula & 0 & 2 & $2(1 \%)$ \\
\hline Humerus & 2 & 0 & $2(1 \%)$ \\
\hline Sternum & 4 & 0 & $4(2 \%)$ \\
\hline Foot & 2 & 0 & $2(1 \%)$ \\
\hline Ribs & 6 & 0 & $6(3 \%)$ \\
\hline \multicolumn{4}{|l|}{ No. of metastasis site } \\
\hline single & 64 & 24 & $88(57 \%)$ \\
\hline multiple & 40 & 26 & $66(43 \%)$ \\
\hline
\end{tabular}


Table 2. Derivation of a symptomatic assessment from a patient-completed questionnaire and distribution of score: symptom score expressed as a percentage of maximum total $20(100 \%)$.

\begin{tabular}{clc}
\hline Parameter & \multicolumn{1}{c}{ Description } & Score \\
\hline \multirow{5}{*}{ Pain } & NRS $=0$ & $\mathbf{0}$ \\
& NRS $=1$ & $\mathbf{1}$ \\
& NRS $=2$ & $\mathbf{2}$ \\
& NRS $=3$ & $\mathbf{3}$ \\
& NRS $=4$ & $\mathbf{4}$ \\
& NRS $=5$ & $\mathbf{5}$ \\
& NRS $=6$ & $\mathbf{6}$ \\
& NRS $=7$ & $\mathbf{7}$ \\
& NRS $=8$ & $\mathbf{8}$ \\
& NRS $=9$ & $\mathbf{9}$ \\
& NRS $=10$ & $\mathbf{1 0}$ \\
Analgesic & None & $\mathbf{0}$ \\
use & Simple analgesic or FANS 1 v/die & $\mathbf{1}$ \\
& Simple analgesic or FANS $>$ 1v/die & $\mathbf{2}$ \\
& Mild opioids 1 v/die & $\mathbf{3}$ \\
& Mild opioids $>1$ v/die & $\mathbf{4}$ \\
& Strong opioids 1 v/die & $\mathbf{5}$ \\
& Strong opioids $>1$ v/die & $\mathbf{6}$ \\
& Normal & $\mathbf{0}$ \\
status & Light work possible & $\mathbf{1}$ \\
& Up and about $>50 \%$ of the day & $\mathbf{2}$ \\
& Confined to bed or to chair $>50 \%$ of the day & $\mathbf{3}$ \\
& Completely bed-bound & $\mathbf{4}$ \\
& & $\mathbf{0}-\mathbf{2 0}$ \\
& &
\end{tabular}

\section{Results}

We calculated the number of patients for each score at several time of our observation (Table 3). From the data collected, the first important consideration is the gradual reduction in number of patients with severe pain (NRS = 8-9-10) in the different phases of observation of both treatment groups. It's interesting to note that in the group of patients treated with $\mathrm{RT}+\mathrm{Z}$ there were fewer patients that started radiation therapy with severe pain $(16 \%$ vs $32 \%$ ), no patient had pain of grade 10 , and a higher proportion of asymptomatic patients ( $12 \%$ vs $4 \%$ ) was observed. In the RT alone group a higher percentage of patients started treatment assuming strong opioid more than once a day (26\% vs $24 \%$ ) and a reduction in number of these patients was about $14 \%$ compared with the reduction of $23.6 \%$ observed in the group RT + Z. Furthermore an increased total score was calculated only in the $6 \%$ of patient belonged to group RT alone. Finally, in the group $\mathrm{RT}+\mathrm{Z}$ responder patients are $52 \%$, compared to $36 \%$ of the RT group, non-responder were $36 \%$ versus $60 \%$ in the RT group (Table 4) The subsequent evaluation found that in the group $\mathrm{RT}+\mathrm{Z}$ responder are $52 \%$, compared to $36 \%$ of the RT group, the non-responder, which include the no-change and progression, accounting for $36 \%$ in the $\mathrm{RT}+\mathrm{Z}$ group, compared to $60 \%$ in the RT group, bearing in mind that the category of patients defined progression, equal to $6 \%$ in the $\mathrm{RT}$, is not represented in the group $\mathrm{RT}+\mathrm{Z}$. We calculated the risk

Table 3. Symptomatic assessment evaluated by a questionnaire completed by patients with the score distribution before, during and after treatment in the two groups.

\begin{tabular}{|c|c|c|c|c|c|c|c|c|c|c|c|c|c|}
\hline \multicolumn{8}{|c|}{ Group RT (104 patients) } & \multicolumn{6}{|c|}{ Group RT + Z (50 patients) } \\
\hline \multirow{2}{*}{ Parameter } & \multirow{2}{*}{ Score } & \multicolumn{6}{|c|}{$\mathrm{N}$ of patients } & \multicolumn{6}{|c|}{$\mathbf{N}$ of patients } \\
\hline & & 1 day & 6 day & 10 day & FU 30 & FU 60 & FU 90 & 1 day & 6 day & 10 day & FU 30 & FU 60 & FU 90 \\
\hline \multirow{10}{*}{ Pain } & $\mathbf{0}$ & 4 & 4 & 4 & 8 & 14 & 16 & 6 & 6 & 6 & 6 & 8 & 8 \\
\hline & 1 & 2 & 0 & 0 & 8 & 6 & 6 & 0 & 0 & 2 & 4 & 4 & 4 \\
\hline & 2 & 0 & 4 & 12 & 12 & 14 & 14 & 0 & 0 & 2 & 10 & 10 & 12 \\
\hline & 3 & 10 & 8 & 8 & 10 & 12 & 10 & 4 & 6 & 4 & 8 & 14 & 12 \\
\hline & 5 & 12 & 10 & 10 & 16 & 14 & 16 & 12 & 14 & 10 & 2 & 4 & 4 \\
\hline & 6 & 12 & 14 & 12 & 10 & 16 & 16 & 8 & 10 & 4 & 2 & 6 & 6 \\
\hline & 7 & 22 & 14 & 16 & 14 & 6 & 8 & 10 & 10 & 6 & 6 & 0 & 0 \\
\hline & 8 & 20 & 22 & 16 & 8 & 10 & 6 & 6 & 2 & 4 & 0 & 0 & 0 \\
\hline & 9 & 8 & 16 & 12 & 4 & 2 & 2 & 2 & 2 & 0 & 0 & 0 & 0 \\
\hline & 10 & 6 & 2 & 2 & 0 & 0 & 0 & 0 & 0 & 0 & 0 & 0 & 0 \\
\hline \multirow{6}{*}{ Analgesic use } & 0 & 12 & 12 & 14 & 14 & 18 & 18 & 10 & 10 & 10 & 12 & 12 & 12 \\
\hline & 2 & 10 & 4 & 4 & 8 & 10 & 10 & 10 & 12 & 10 & 4 & 6 & 6 \\
\hline & 3 & 12 & 14 & 16 & 16 & 16 & 16 & 4 & 4 & 2 & 6 & 6 & 4 \\
\hline & 4 & 14 & 16 & 18 & 16 & 16 & 16 & 8 & 8 & 8 & 10 & 10 & 10 \\
\hline & 5 & 18 & 14 & 8 & 28 & 24 & 24 & 4 & 4 & 6 & 8 & 6 & 6 \\
\hline & 6 & 28 & 34 & 36 & 14 & 14 & 14 & 12 & 12 & 10 & 2 & 2 & 2 \\
\hline \multirow{5}{*}{$\begin{array}{l}\text { Performance } \\
\text { status }\end{array}$} & 0 & 8 & 8 & 8 & 8 & 14 & 14 & 4 & 4 & 6 & 8 & 8 & 8 \\
\hline & 1 & 8 & 8 & 20 & 42 & 40 & 42 & 12 & 12 & 12 & 24 & 24 & 24 \\
\hline & 2 & 56 & 52 & 46 & 36 & 30 & 30 & 26 & 26 & 28 & 16 & 16 & 16 \\
\hline & 3 & 32 & 34 & 30 & 18 & 14 & 14 & 8 & 8 & 4 & 2 & 2 & 2 \\
\hline & 4 & 0 & 0 & 0 & 0 & 4 & 4 & 0 & 0 & 0 & 0 & 0 & 0 \\
\hline
\end{tabular}


Table 4. Subjective response to treatment.

\begin{tabular}{|c|c|c|c|c|c|c|c|c|}
\hline \multirow{2}{*}{$\begin{array}{l}\text { Tumour } \\
\text { Type }\end{array}$} & \multicolumn{4}{|c|}{ RT } & \multicolumn{4}{|c|}{$\mathbf{R T}+\mathbf{Z}$} \\
\hline & $\begin{array}{c}\text { Responders } \\
(>20 \% \\
\text { reduction) }\end{array}$ & $\begin{array}{l}\text { No-change } \\
(0 \%-20 \% \\
\text { reduction) }\end{array}$ & $\begin{array}{c}\text { Progression } \\
\text { (increase in pain) }\end{array}$ & Asymptomatic & $\begin{array}{c}\text { Responders } \\
(>20 \% \\
\text { reduction) }\end{array}$ & $\begin{array}{l}\text { No-change } \\
(0 \%-20 \% \\
\text { reduction) }\end{array}$ & $\begin{array}{c}\text { Progression } \\
\text { (increasein pain) }\end{array}$ & Asymptomatic \\
\hline Breast & 12 & 14 & 2 & 2 & 10 & 6 & 0 & 4 \\
\hline Prostate & 2 & 4 & 0 & 0 & 6 & 6 & 0 & 2 \\
\hline Lung & 4 & 16 & 0 & 0 & 8 & 2 & 0 & 0 \\
\hline Liver & 6 & 2 & 0 & 0 & 0 & 0 & 0 & 0 \\
\hline Colon & 2 & 2 & 0 & 0 & 2 & 2 & 0 & 0 \\
\hline Rectum & 0 & 4 & 0 & 0 & 0 & 0 & 0 & 0 \\
\hline Bladder & 0 & 6 & 2 & 0 & 0 & 0 & 0 & 0 \\
\hline Kidney & 4 & 2 & 0 & 0 & 0 & 0 & 0 & 0 \\
\hline Larynx & 4 & 0 & 0 & 0 & 0 & 0 & 0 & 0 \\
\hline Pleura & 0 & 2 & 2 & 0 & 0 & 0 & 0 & 0 \\
\hline Thyroid & 2 & 0 & 0 & 0 & 0 & 2 & 0 & 0 \\
\hline Parotid & 0 & 0 & 0 & 2 & 0 & 0 & 0 & 0 \\
\hline Oral & 0 & 2 & 0 & 0 & 0 & 0 & 0 & 0 \\
\hline Unknow & 2 & 2 & 0 & 0 & 0 & 0 & 0 & 0 \\
\hline Tot & 38/104 & $56 / 104$ & 6/104 & $4 / 104$ & $26 / 50$ & $18 / 50$ & $0 / 50$ & $6 / 50$ \\
\hline$\%$ & $36 \%$ & $54 \%$ & $6 \%$ & $4 \%$ & $52 \%$ & $36 \%$ & $0 \%$ & $12 \%$ \\
\hline
\end{tabular}

of adverse events in the RT group and found $\mathrm{P}_{\mathrm{Z}}$ (risk adverse $\mathrm{RT}+\mathrm{Z})=0.36$ with $\mathrm{O}_{\mathrm{Z}}$ (Odds of $\left.\mathrm{RT}+\mathrm{Z}\right)=0.56$, while the risk of adverse events in the RT group showed Pc (risk adverse RT) $=0.60$ with Oc $($ Odds of RT $)=1.5$. We have at this point, calculated the odds ratio OR = 0.37 , which showed a value in favor of treatment $\mathrm{RT}+\mathrm{Z}$. Moreover we calculated the average reduction in the total score in the two groups at different observation times and we have seen that in the first group as well as having a mean value lower than the second group, having also a greater average reduction in score (Figure 1). From our observational study, it is relevant a clear potentiation of benefit effects related to palliative radiation therapy in patients receiving also bisphosphonate therapy, so obtaining a better control over pain, a decreased need for pain relief and consequently an improved quality of life.

\section{Discussion}

Metastatic bone disease is the major cause of morbidity in patients with cancer. Bone fractures, hypercalcaemia, neurologic deficits and reduced activity associated with bone metastases result in an overall compromise of patient's quality of life.

Bone is not an inert body, undergoes continuous remodeling process with phases of resorption and formation [8]. This process is closely coordinated by osteoclasts,

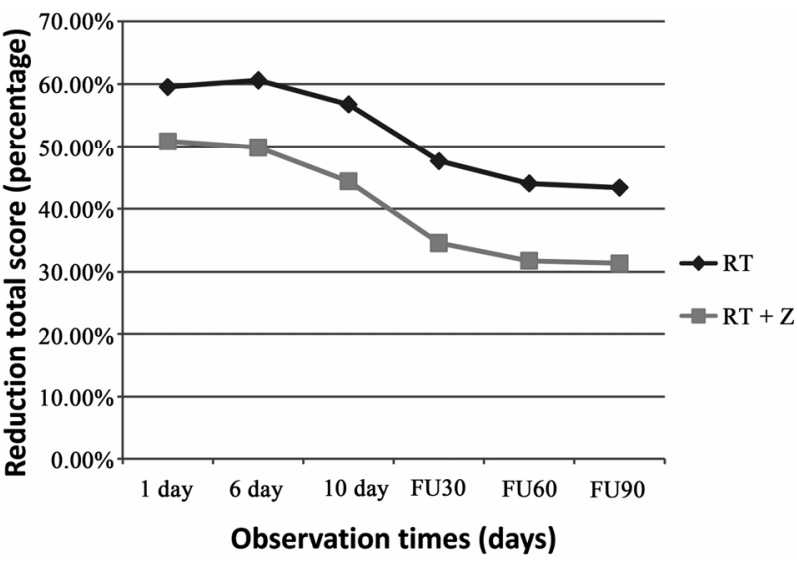

Figure 1. Changes in pain score. Mean value are shown total score calculated by combining the individual scores of pain, analgesic consumption and WHO performance status.

responsible for the phase of resorption, and by osteoblasts regulating a more prolonged phase of bone formation. When the bone becomes the seat of metastases, its normal process of turnover is compromised [5].

Bone resorption and the regulation of osteoclastic activity is influenced by RANK-L/RANK/OPG system. The RANK ligand (RANK-L), belonging to the TNF superfamily, is the key mediator of the formation, function and survival of osteoclasts; it is expressed both in the 
form of a membrane on the surface of stromal cells/osteoblasts, both in a soluble form. RANK-L binding to its receptor RANK on osteoclast lineage cells, stimulates the activation and differentiation of osteoclasts, inhibiting apoptosis [9]. The osteoprotegerin (OPG) is instead able to bind RANK-L inhibiting its function, leading to an inhibition of bone resorption [10]. The increase in the ratio RANKL/OPG is the basis of the increase in bone resorption, the mechanism leading to formation of bone metastases and in their maintenance [11]. Bisphosphonates have the ability to bind and so inhibit RANK-L.

The analgesic effect of radiotherapy in the treatment of bone metastases, is explained by a cytocidal action deriving from ionizing tumor cells; this result in reducing mechanical compression and infiltration of bone tissue. Furthermore, radiation reduce the production of cytokines involved in the stimulation of receptors responsible of pain. The precocity of palliation, within 48 hours of treatment, which occurs in about $25 \%$ of patients, and that can not be attributed to the effective reduction of tumor mass, involve other mechanisms, probably, the action target of ionizing radiation on the regulatory system osteoclasts and RANK/RANK-L. From the latter, could derive the mutual enhancement of radiation therapy and therapy with bisphosphonates. This hypothesis is supported by the results of Hoskin et al. which showed that the reduction of pain after radiotherapy for bone metastases is associated with low urinary concentrations of pyridinoline and deoxypyridinoline, markers of bone resorption [12].

The treatment of pain related to bone metastases requires a multidisciplinary approach and the radiation therapy is considered a standard treatment used in bone metastases, when there is pain, risk of pathological fracture, and spinal cord compression. It's an effective symptomatic treatment of bone pain localized [13,14], resulting in a palliative effect within 4 - 6 weeks in about $80 \%$ of patients treated. Bisphosphonates have an increasingly important role in oncology, management of bone metastases, in the prevention of skeletal complications. They showed to reduce skeletal morbidity in breast cancer, the level of pain, analgesic consumption, and lead to an improvement in quality of life of the patient [15]. Bisphosphonates, in addition to inhibiting the function of osteoclasts, they also cause apoptosis, but it seems to have a direct effect on the type of apoptotic tumor cells, as has been demonstrated by studies in vitro on tumor cells of breast cancer, the prostate, melanoma, osteosarcoma, myeloma [16-21]. Radiotherapy and bisphosphonates, therefore, through their effects on cellular homeostasis, play a major role in the treatment of bone metastases. In addition, due to the effect of bisphosphonates radiosensitizer, the combination of bisphosphonates and radiation therapy can improve the effectiveness of the latter [22]. Krempiem et al. have investigated the possible benefit of this combination on the process of recalcification and stabilization of osteolytic bone metastases in animal tumor models, demonstrating that the addition of early bisphosphonate, clodronate in this case and radiation therapy, significantly improved the density and bone microstructural parameters [23]. Kouloulias et al. in a clinical trial of 33 patients with bone metastases from breast cancer, showed that the combination of radiation therapy and treatment with bisphosphonates induced a clinical improvement after 6 months of therapy compared with the control baseline in terms of bone density, pain control, performance status, biochemical markers of bone resorption and quality of life. They also showed a higher clinical benefit-instrumental on bone recalcification in the combination of radiotherapy and bisphosphonates, compared to that obtained by radiotherapy alone [24]. Currently, many patients receiving bisphosphonates in combination with radiation therapy, as documented by a study by Rosen et al. [25], and a review of Hoskin [6]. Our retrospective observational study finds substantial benefits in terms of pain reduction and improvement of quality of life in patients undergoing the two treatments concurrently.The clinical data, confirmed the effectiveness of bisphosphonates in pain from bone metastases and the prevention of skeletal related events to them, but the most important factor that comes from our observations is that the interaction between radiotherapy and treatment with bisphosphonates leads to an increased response to radiation treatment, with a greater reduction in pain, a reduced need for pain relief and better performance status.

\section{REFERENCES}

[1] R. G. Twycross and S. Fairfield, "Pain in Far-Advanced Cancer,” Pain, Vol. 14, No. 3, 1982, pp. 303-310. doi:10.1016/0304-3959(82)90137-3

[2] J. N. Morris, V. Mor, R. J. Goldberg, S. Sherwood, D. S. Greer and J. Hiris, "The Effect of Treatment Setting and Patient Characteristics of Pain in Terminal Cancer Patients: A Report from the National Hospice Study,” Journal of Chronic Diseases, Vol. 39, No. 1, 1986, pp. 27-35. doi:10.1016/0021-9681(86)90104-9

[3] F. J. Brescia, D. Adler, G. Gray, M. A. Ryan and J. M. Cimino, "Hospitalized Advanced Cancer Patients: A Profil,” Journal of Pain Symptom Manage, Vol. 5, No. 4, 1990, pp. 221-227. doi:10.1016/0885-3924(90)90015-C

[4] A. J. Nora, "Radiation for Bone Metastases," Cancer, Vol. 80, No. S8, 1997, pp. 1628-1645. doi:10.1002/(SICI)1097-0142(19971015)80:8+<1628::AI D-CNCR13>3.0.CO;2-1

[5] S. Mercadante, "Malignant Bone Pain: Pathophysiology and Treatment," Pain, Vol. 69, No. 1, 1997, pp. 1-18. doi:10.1016/S0304-3959(96)03267-8 
[6] P. J. Hoskin, "Bisphosphonates and Radiation Therapy for Palliation of Metastatic Bone Disease," Cancer Treatment Reviews, Vol. 29, No. 4, 2003, pp. 321-327. doi:10.1016/S0305-7372(03)00013-6

[7] G. Arcangeli, G. Giovinazzo, B. Saracino, L. D’Angelo, G. Giannarelli, G. Arcangeli and A. Micheli, "Radiation Therapy in the Management of Symptomatic Bone Metastases: The Effect of Total Dose and Histology on Pain Relief and Response Duration,” International Journal of Radiation Oncology, Vol. 42, No. 5, 1998, pp. 1119-1126. doi:10.1016/S0360-3016(98)00264-8

[8] G. R. Mundy, "Bone Resorption and Turnover in Health and Disease,” Bone, Vol. 8, 1987, pp. S9-S16.

[9] H. Hsu, D. L. Lacey, C. R. Dunstan, I. Solovyev, A. Colombero, E. Timms, H. L. Tan, G. Elliott, M. J. Kelley, I. Sarosi, L. Wang, X. Z. Xia, R. Elliott, L. Chiu, T. Black, S. Scully, C. Capparelli, S. Morony, G. Shimamoto, M. B. Bass and W. J. Boyle, “Tumour Necrosis Factor Receptor Family Member RANK Mediates Osteoclast Differentiation and Activation Induced by Osteoprotegerin Ligand," Proceedings of the National Academy of Sciences of the USA, Vol. 96, No. 7, 1999, pp. 3540-3545. doi:10.1073/pnas.96.7.3540

[10] W. S. Simonet, D. L. Lacey, C. R. Dunstan, M. Kelley, M. S. Chang, R. Lùthy, H. Q. Nguyen, S. Wooden, L. Bennett, T. Boone, G. Shimamoto, M. DeRose, R. Elliott, A. Colombero, H. L. Tan, J. Sullivan, E. Davy, N. Bucay, L. Renshaw-Gegg, T. M. Hughes, D. Hill, W. Pattison, P. Campbell, S. Sander, G. Van, J. Tarpley, P. Derby, R. Lee and W. J. Boyle, "Osteoprotegerin: A Novel Secreted Protein Involved in the Regulation of Bone Density," Cell, Vol. 89, No. 2, 1997, pp. 309-319. doi:10.1016/S0092-8674(00)80209-3

[11] T. A. Guise, J. J. Yin, R. J. Thomas, M. Dallas, Y. Cui and M. T. Gillespie, "Parathyroid Hormone-Related Protein (PTHrP)(1-139) Isoform is Efficiently Secreted in Vitro and Enhances Breast Cancer Metastasis to Bone in Vivo,” Bone, Vol. 30, No. 5, 2002, pp. 670-676. doi:10.1016/S8756-3282(02)00685-3

[12] P. J. Hoskin, M. R. Stratford, L. K. Folkes, J. Regan and J. R. Yarnold, "Effect of Local Radiotherapy for Bone Pain on Urinary Markers of Osteoclast Activity," Lancet, Vol. 355, No. 9213, 2000, pp. 1428-1429. doi:10.1016/S0140-6736(00)02144-9

[13] H. S. Poulson, O. S. Nielsen, M. Klee and M. Rorth, "Palliative Irradiation of Bone Metastases," Cancer Treatment Reviews, Vol. 16, No. 1, 1989, pp. 41-48. doi:10.1016/0305-7372(89)90003-0

[14] P. J. Hoskin, "Radiotherapy in the Management of Bone Pain," Clinical Orthopaedics and Related Research, Vol. 312, No. 1, 1995, pp. 105-119.

[15] E. Coleman-Robert, "Management of Bone Metastases," The Oncologist, Vol. 5, No. 6, 2000, pp. 465-466.

[16] S. G. Senaratne, G. Pirianov, J. L. Mansi, T. R. Arnett and K. W. Colston, "Bisphosphonates Induce Apoptosis in Human Breast Cancer Cell Lines,” British Journal of Cancer, Vol. 82, No. 8, 2000, pp. 366-371.
[17] S. P. Jagdev, R. E. Coleman, C. M. Shipman, H. A. Rostami and P. I. Croucher, "The Bisphosphonate, Zoledronic Acid, Induces Apoptosis of Breast Cancer Cells: Evidence for Synergy with Paclitaxel,” British Journal of Cancer, Vol. 84, No. 8, 2001, pp. 1126-1134. doi:10.1054/bjoc.2001.1727

[18] M. V. Lee, E. M. Fong, F. R. Singer and R. S. Guenette, "Bisphosphonate Treatment Inhibits the Growth of Prostate Cancer Cells,” Cancer Research, Vol. 61, No. 6, 2001, pp. 2602-2608.

[19] C. Riebeling, A. M. Forsea, M. Raisova, C. E. Orfanos and C. C. Geilen, "The Bisphosphonate Pamidronate Induces Apoptosis in Human Melanoma Cells in Vitro," British Journal of Cancer, Vol. 87, No. 3, 2002, pp. 366371. doi:10.1038/sj.bjc.6600476

[20] P. S. Mackie, J. L. Fisher, H. Zhou and P. F. Choong, "Bisphosphonates Regulate Cell Growth and Gene Expression in the UMR 106-101 Clonal Rat Osteosarcoma Cell Line,” British Journal of Cancer, Vol. 84, No. 7, 2001, pp. 951-958. doi:10.1054/bjoc.2000.1679

[21] C. M. Shipman, P. I. Croucher, R. G. Russell, M. H. Helfrich and M. J. Rogers, "The Bisphosphonate Incadronate (YM175) Causes Apoptosis of Human Myeloma Cells in Vitro by Inhibiting the Mevalonate Pathway," Cancer Research, Vol. 58, No. 23, 1998, pp. 5294-5297.

[22] A. Ugur-Ural, F. Avcu and Y. Baran, "Bisphosphonate Treatment and Radiotherapy in Metastatic Breast Cancer,” Medical Oncology, Vol. 25, No. 3, 2008, pp. 350355. doi:10.1007/s12032-008-9044-4

[23] R. Krempiem, P. E. Huber, W. Harms, M. Treiber, M. Wannenmacher and B. Krempiem, "Combination of Early Bisphosphonates Administration and Irradiation Leads to Improved Remineralization and Restabilization of Osteolytic Bone Metastases in an Animal Tumor Model," Cancer, Vol. 98, No. 6, 2003, pp. 1318-1324. doi:10.1002/cncr.11646

[24] V. Kouloulias, G. Matsopoulos, J. Kouvaris, C. Dardoufas, A. Bottmley, M. Varela, N. Uzunoglu, C. Antypas, A. Metafa, A. Moulopoulos, P. Sandilos and L. Vlahos, "Radiotherapy in Conjunction with Intravenous Infusion of 180 mg Ofsodium Pamidronate in Management of Osteolytic Metastases from Breast Cancer: Clinical Evaluation, Biochemical Markers, Quality of Life, and Monitoring of Recalcification Using Assessments of Graylevel Histogram in Plain Radiographs," International Journal of Radiation Oncology, Biology, Physics, Vol. 57, No. 1, 2003, pp. 143-157. doi:10.1016/S0360-3016(03)00525-X

[25] L. S. Rosen, D. Gordon, S. Tchekmedyian, R. Yanagihara, V. Hirsh, M. Krzakowski, M. Pawlicki, P. de Souza, M. Zheng, G. Urbanowitz, D. Reitsma and J. J. Seaman, "Zoledronic Acid Versus Placebo in the Treatment of Skeletal Metastases in Patients with Lung Cancer and Other Solid Tumors: A Phase III, Double-Blind, Randomized Trial. The Zoledronic Acid Lung Cancer and Other Solid Tumors Study Group,” Journal of Clinical Oncology, Vol. 21, No. 16, 2003, pp. 3150-3157. doi:10.1200/JCO.2003.04.105 